\title{
The Hadopi Act vs. the Global License as a Psychological Game
}

\author{
Fabienne Oguer \\ University of Franche-Comté \\ U.F.R. S.J.E.P.G., 25030 Besançon Cedex, France \\ E-mail: fabienne.oguer@univ-fcomte.fr
}

Received: January 21, $2011 \quad$ Accepted: February 14, $2011 \quad$ doi:10.5539/res.v3n1p79

\begin{abstract}
This article examines the digital industry's decision to enforce the Hadopi Act rather than support the global license to address the concerns resulting from the piracy of digital materials through Internet online sharing networks. Using a game-theoretic analysis and applying Nash equilibrium, it is determined that the situation does not justify the digital industry's choice of adopting the Hadopi Act. By introducing a psychological game-theoretic approach to take into account the awareness campaign of the negative impact of piracy on digital industry's business, it was determined that the choice of the Hadopi Act is appropriate if the Internet potential pirate is sufficiently guilt averse.
\end{abstract}

Keywords: Digital piracy, Guilt, Psychological game, Trust

\section{Introduction}

The Hadopi Act is a French legal action that prohibits the illegal copying of digital material by participants in peer-to-peer (P2P) file-sharing networks. This law is in response to the concern of the digital industry over the impact of piracy on its business. The digital industry has called for measures to contain the expansion of digital piracy.

The Hadopi Act provides for the prosecution of consumers using the P2P exchange service and allows for the disconnection of the Internet line used for the illegal online sharing of files after sufficient warnings. Publicity surrounding the legal sanctions comes with an awareness of the negative impact of piracy on the digital industry's business to justify lawsuits filed against sharers, to convert digital pirates and to dissuade potential ones from pirating.

An alternative way to reduce losses suffered by the digital industry due to pirating is being studied. It consists of a global license that permits the downloading of digital files in return for a fee paid to the digital industry. The digital industry, however, deems this solution inadequate claiming that the total amount collected is relatively small compared to its loss of income.

Three types of fees are possible. In the case of a universal fee, the Internet user pays a lump sum for the use of the Internet, irrespective of purpose. For an optional fee, the user pays a lump sum if he intends to download files from the Internet. Recently, a French deputy requested a gradual fee, which would require the user to pay according to his downloading of Internet files.

The optional fee and the gradual fee are similar to the Hadopi Act with respect to piracy incentives. Gopal, Sanders, Bhattacharjee, Agrawal and Wagner (2004) and Rayna (2007) show that following Samuelson (1954), digital goods are collective goods due to their inherent properties of non-rivalry and non-excludability. Digital pirating behavior is a free-riding behavior as the Internet user copies digital goods without paying for them. Piracy incentive concerns those Internet users who have access at little cost to pirating technologies. This same concern exists as well for the optional or the gradual license in contrast to the universal license that imposes a fixed fee.

A game-theoretic analysis can shed new light on the digital industry's choice (through the government legislative body) of the Hadopi Act rather than the global license. It includes the choice of an Internet potential pirate who may or may not, in either case or in both cases, adopt a digital pirating behavior. Dejean, Pénard and Suire (2010) estimate that the majority of Internet users are not digital pirates. They further note that, in response to the Hadopi Act, Internet pirates shift to other pirating practices. 
The study uses a psychological game-theoretic approach to take into account the awareness by Internet users of the negative impact of piracy on the digital industry's business. The psychological game-theory framework, as developed by Geanakoplos, Pearce, and Stacchetti (1989) and extended by Battigalli and Dufwenberg (2009), allows for the inclusion of feelings of guilt. That is, the Internet pirate may feel guilty because he believes that the digital industry expects that he will not pirate materials. According to Geanakoplos et al., a psychological game-theoretic approach is appropriate and suitable for analyzing belief-dependent considerations in situations where gains are defined by choices and by the hierarchy of the players' beliefs about those choices. Guilty feelings about piracy reduce the gains for the Internet potential pirate when he adopts piracy behavior. Thus, the analysis reflects that the digital industry's choice of the Hadopi Act is appropriate if the Internet potential pirate is sufficiently guilt averse.

Section 2.1 models the choice of the digital industry between the Hadopi Act and the universal global license and the resulting pirating behavior of the Internet potential pirate. It demonstrates that the pattern of gains corresponds to a trust game in which Nash (backward induction) equilibrium does not justify the digital industry's choice of the Hadopi Act. Section 2.2 introduces the impact of awareness campaigns. It shows that the psychological trust game where the Internet potential pirate is sufficiently guilt averse may explain the decision by the digital industry to adopt the Hadopi Act. Section 3.1 similarly studies the behaviors of the digital industry and the Internet potential pirate when the digital industry chooses between the Hadopi Act and the optional global license or the gradual global license. It originates from a trust game and shows that Nash equilibrium still does not explain the choice of the Hadopi Act. Section 3.2 shows that the psychological game with sufficient guilt aversion may justify the choice of the digital industry to enforce the Hadopi Act. Section 4 concludes.

\section{The Hadopi Act vs. the Universal Global License}

\subsection{The Trust Game}

The digital industry plays first, through the government legislative body, choosing between the global license and the Hadopi Act. Suppose that the global license to be implemented is a universal one. If the digital industry chooses the global license, the game has no second period as the Internet potential pirate has no piracy incentive. If the digital industry chooses the Hadopi Act, the Internet potential pirate chooses between No Piracy and Piracy.

Let $0,1 / 2$ and 1 be the players' possible gains according to their choices. When the digital industry chooses the Hadopi Act, the industry's gain is 1 if the Internet potential pirate chooses No Piracy or 0 when she chooses Piracy. When the industry chooses the global license, the industry obtains an intermediate gain of $1 / 2$. Conversely, when the digital industry chooses the Hadopi Act, the Internet potential pirate's gain is 1 if she chooses Piracy and 0 if she chooses No Piracy because she cannot get digital resources. When the digital industry chooses the global license, the Internet potential pirate has an intermediate gain of $1 / 2$ as she can obtain digital goods at little cost.

This two-period, two-player game is a trust game because, according to Bacharach, Guerra and Zizzo (2001), the gains satisfy the three typical inequalities of Exposure, Improvement and Temptation. First, when the digital industry chooses the Hadopi Act rather than the global license, the industry exposes itself to the risk that the Internet potential pirate shifts to other pirating practices; thus, the industry would have a gain of 0 rather than $1 / 2$. Secondly, when the digital industry chooses the Hadopi Act rather than the global license, the industry can improve its gain if the Internet potential pirate adopts a non-pirating behavior; therefore, the industry would have a gain of 1 rather than $1 / 2$. Thirdly, the Internet potential pirate has a piracy incentive when the digital industry chooses the Hadopi Act; thus, she would have a gain of 1 rather than 0.

This trust game does not produce the common dilemma because, according to Bacharach et al. (2001), it does not satisfy the additional typical inequality of Mutual Gain. Indeed, compared to the choice of a global license, the strategies (Hadopi Act; No Piracy) do not improve the gain for the Internet potential pirate. Thus, contrary to Kreps' trust game (1990), Rabin's partnership game (1993) and Dufwenberg's marital partnership game (2002), the trust game between the digital industry and the Internet potential pirate is not a one-sided version of the prisoners' dilemma game. According to Bacharach et al. (2001), not all trust games satisfy this fourth property.

The extensive form and the equilibrium path of this dynamic game with complete information are presented in Figure 1. Its backward induction solution (Global License; Piracy) does not explain why the digital industry chooses the Hadopi Act. 


\subsection{The Psychological Trust Game with Guilt}

What may explain the digital industry's choice of the Hadopi Act is the awareness campaign of the antisocial nature of piracy behavior. According to Balestrino (2008), Internet pirates are not aware of their antisocial behavior. A psychological game approach is necessary to integer guilt feelings for the Internet potential pirate when she adopts a piracy behavior.

Let q be the probability that the Internet potential pirate plays No Piracy, let $r$ be the digital industry's belief about the probability $q$ and let $\mathrm{s}$ be the potential pirate's belief about the digital industry's expectation $\mathrm{r}$ of her choice q. As in Dufwenberg's (2002) study of marital partnership, the more the potential pirate believes that the industry believes she will exhibit non-pirating behavior, the more guilty she feels when she adopts a piracy practice, thus reducing her gain. Let $\gamma$ be guilt sensitivity of the Internet potential pirate. Her gain is $1-\gamma \mathrm{s}$ when she plays Piracy. The extensive form of this psychological trust game is presented in Figure 2.

Suppose first that $\gamma=2$. Then this psychological trust game has two psychological Nash equilibriums. In the first, $\mathrm{q}=\mathrm{r}=\mathrm{s}=0$ such that the equilibrium strategies are (Global License; Piracy). In the other, $\mathrm{q}=\mathrm{r}=\mathrm{s}=1$ and the equilibrium strategies are (Hadopi Act; No Piracy). The second equilibrium explains the digital industry's observed choice of the Hadopi Act.

Suppose now that the Internet potential pirate is less sensitive to guilt, e.g., $\gamma=0.5$. The game has only one psychological equilibrium ( Global License; Piracy). Hence, the Hadopi Act is no longer an equilibrium strategy if the Internet potential pirate is not sufficiently guilt averse.

\section{The Hadopi Act vs. the Optional or Gradual Global License}

\subsection{The Game}

Suppose now that the global license is an optional or a gradual one. When the digital industry chooses a global license, the Internet potential pirate may choose between No Piracy and Piracy as for the Hadopi Act as she may pretend that she does not download or that she downloads less than she actually does, and, thereby, adopt a piracy behavior.

In the case of the gradual global license, let $\mathrm{x}(\mathrm{y})$ be the digital industry (the Internet potential pirate) gain when the digital industry chooses the global license and the Internet potential pirate chooses Piracy. Then $0 \leq \mathrm{x}<1 / 2$ and $1 / 2<y \leq 1$. When the Internet potential pirate adopts a non-pirating behavior, both the industry and the potential pirate obtain an intermediary gain of $1 / 2$.

The optional global license is a specific case of the gradual global license because when the Internet potential pirate pretends she does not download and adopts a piracy behavior, her gain is 1 and the digital industry's gain is 0 .

The game is a trust-type game because when the digital industry chooses the Hadopi Act rather than a global license, the industry may be worse off or better off depending on the piracy behavior of the Internet potential pirate. Its extensive form and its equilibrium path are presented in Figure 3 (indifference of the digital industry in the case of the optional global license is neglected). As for a universal global license, its backward induction solution (Global License; Piracy, Piracy) does not explain the digital industry's observed choice of the Hadopi Act.

\subsection{The Psychological Game with Guilt}

Let us introduce guilt feelings for the Internet potential pirate when she opts for Piracy. Let (q, r, s, $\gamma$ ) and (q', r', $\left.s^{\prime}, \gamma^{\prime}\right)$ be the respective values for probabilities, beliefs and guilt sensitivity whether the digital industry chooses the Hadopi Act or a global license. The extensive form of the psychological game is presented in Figure 4.

Suppose first that $\gamma=\gamma^{\prime}=2$. This psychological game has four Nash equilibriums, (Global License; Piracy, Piracy), (Global License; No Piracy, Piracy), (Hadopi Act; Piracy, No Piracy) and (Hadopi Act; No Piracy, No piracy). The last two equilibriums explain the digital industry's choice to adopt the Hadopi Act.

As for a universal global license, if the Internet potential pirate is not sufficiently guilt averse, e.g., for $\gamma=0.5$, then the Hadopi Act is no longer an equilibrium strategy as the game now has only two psychological equilibriums (Global License; Piracy, Piracy) and (Global License; No Piracy, Piracy).

\section{Conclusion}

The expanse of the Internet and the potential for digital piracy require the development of economic models for both the digital industry and the Internet user. Bhattacharjee, Gopal, Lertwachara and Marsden (2003) model music purchasing and pirating behavior of consumers using different pricing models to determine 
revenue-maximizing strategies for the seller in the face of online music piracy. Gopal et al. (2004) present a behavioral model of digital audio piracy where the determinants are age, gender, ethical predispositions and money saved using an MP3. Rayna (2007) shows how the public nature of digital goods explains the development of the piracy phenomenon. Regner and Barria (2009) studied the relationship between the online music label Magnatune and the potential customer. They find that the online label's pre-purchase access to music enables potential customers to determine the true value of this experience good, and they explain why an informed customer sets a price higher than the minimum price. They employ a psychological game-theoretic approach where the customer has reciprocity considerations, according to Rabin (1993), such that the potential customer helps (punishes) a kind (unkind) label's pre-purchase behavior. Such reciprocity considerations would similarly lead an Internet potential pirate to adopt a piracy behavior or a non-pirating behavior depending on whether the digital industry chooses the Hadopi Act or a global license.

While some countries, such as the U.S. and the UK, have chosen prosecution against piracy, Brazil has considered the choice of global license and Belgium has studied both options. Bhattacharjee, Gopal, Lertwachara and Marsden (2006) studied the impact of legal action against online music sharing and conclude that lawsuits slow down file-sharing behavior. Dejean et al. (2010) have studied the impact of the Hadopi Act on the piracy behavior of the French Internet user. As well as the tendency that they observed to shift to other pirating practices, they argue that disconnecting the Internet lines of offenders would reduce sales of digital goods on the Internet as the Internet potential pirate is also a digital purchaser.

\section{References}

Bacharach, M., Guerra, G., \& Zizzo, D. J. (2001). Is trust self-fulfilling? An experimental study. (Discussion Paper, University of Oxford). [Online] Available: http://www.economics.ox.ac.uk/research/WP/PDF/paper076.pdf

Balestrino, A. (2008). It is a theft but not a crime. European Journal of Political Economy, 24, 455-469.

Battigalli, P., \& Dufwenberg, M. (2009). Dynamic psychological games. Journal of Economic Theory, 144, $1-35$.

Bhattacharjee, S., Gopal, R. D., Lertwachara, K., \& Marsden, J. R. (2003). Economic of online music. ICEC '03 Proceedings of the 5th international conference on Electronic commerce.

Bhattacharjee, S., Gopal, R. D., Lertwachara, K., \& Marsden, J. R. (2006). Impact of legal threats on online music sharing activity: an analysis of music industry legal actions. Journal of Law and Economics, 49, 91-114.

Dejean, S., Pénard, T., \& Suire, R. (2010). Une première évaluation des effets de la loi Hadopi sur les pratiques des Internautes français. [Online] Available: http://www.lesechos.fr/medias/2010/0309/300415066.pdf.

Dufwenberg, M. (2002). Marital investments, time consistency and emotions. Journal of Economic Behavior and Organization, 48, 57-69.

Geanakoplos, J., Pearce, D., \& Stacchetti, E. (1989). Psychological games and sequential rationality. Games and Economic Behavior, 1, 60-79.

Gopal, R. D., Sanders, G. L., Bhattacharjee, S., Agrawal, M., \& Wagner, S. C. (2004). A behavioural model of digital music piracy. Journal of Organizational Computing and Electronic Commerce, 14, 89-105.

Kreps, D. (1990). Corporate culture and economic theory. In J. E. Alt, \& K. A. Shepsle (Eds.), Perspectives on positive political economy (pp. 90-143). Cambridge: Cambridge University Press.

Rabin, M. (1993). Incorporating fairness into game theory and economics. American Economic Review, 83, 1281-1302.

Rayna, T. (2007). Digital goods as public durable goods. (Doctoral dissertation, University of Aix-Marseille III - Paul Cézanne). [Online] Available: http://pubs.doc.ic.ac.uk/rayna-thesis/rayna-thesis.pdf

Regner, T., \& Barria, J. A. (2009). Do consumers pay voluntarily? The case of online music. Journal of Economic Behavior and Organization, 71, 395-406.

Samuelson, P. A. (1954). The pure theory of public expenditure. The Review of Economics and Statistics, 36, 387-389. 


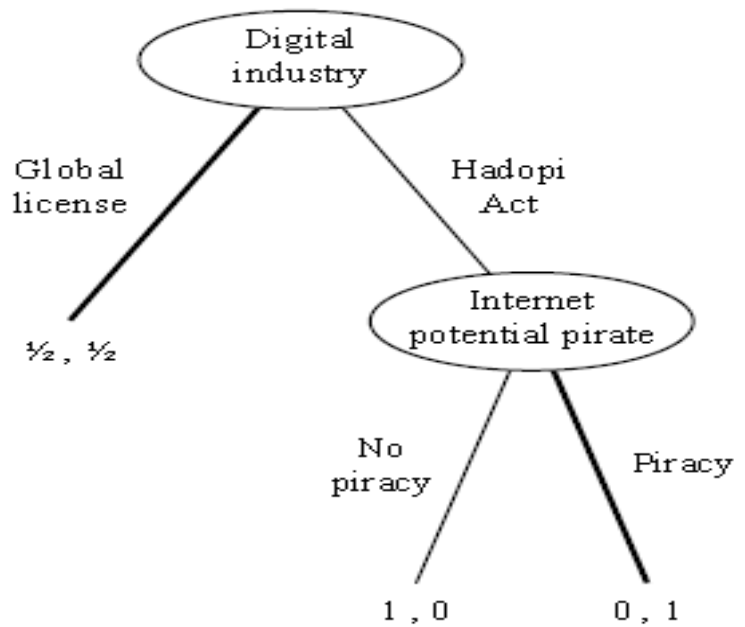

Figure 1. The trust game and its equilibrium path for the universal global license

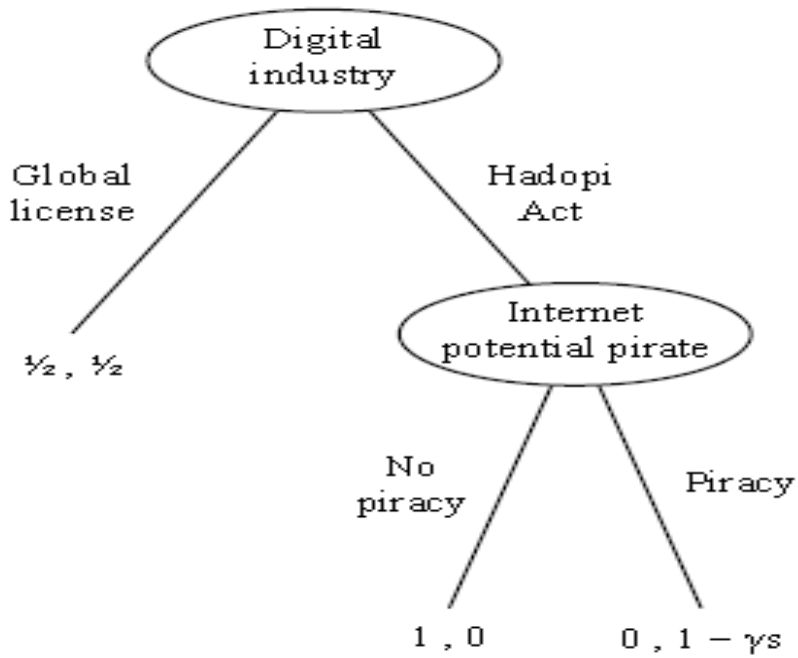

Figure 2. The psychological trust game for the universal global license 


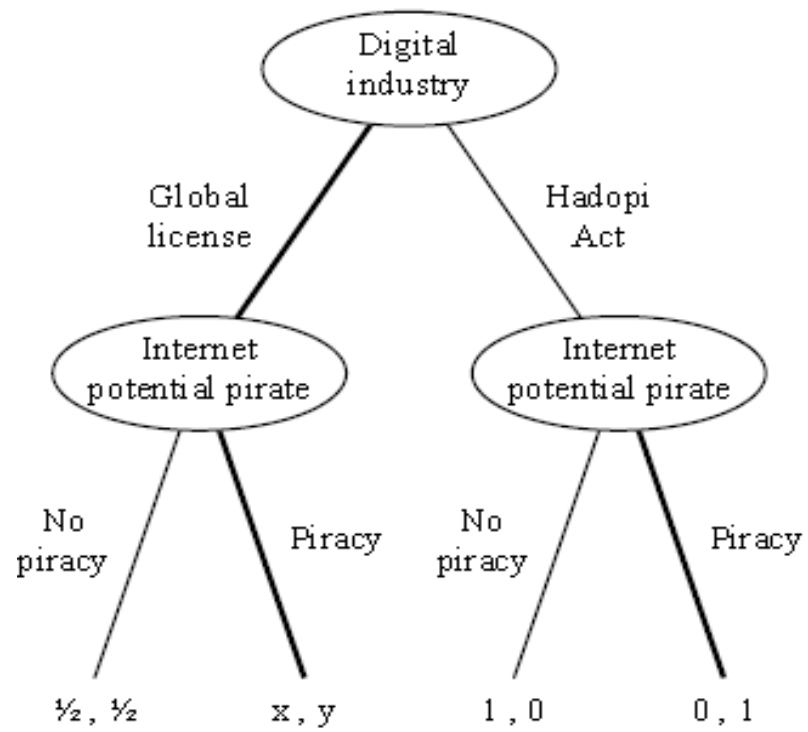

Figure 3. The game and its equilibrium path for the optional or the gradual global license

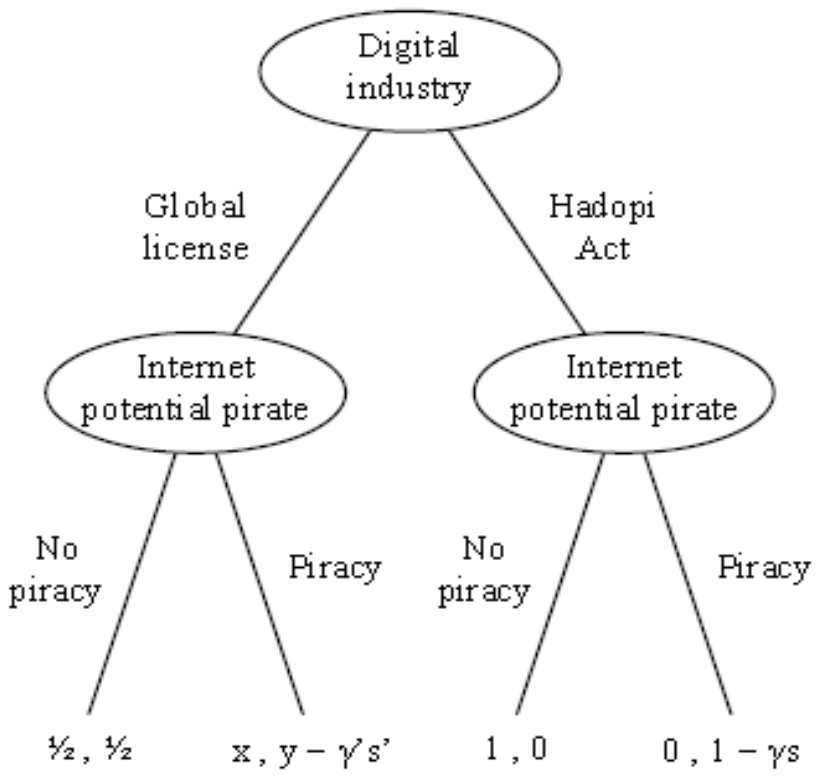

Figure 4. The psychological game for the optional or the gradual global license 